\title{
Aplicação de Ferramentas da Qualidade para Análise e Solução de não Conformidades em uma Indústria de Alumínio
}

Application of quality tools for analysis and solution of nonconformities in an aluminum industry

\author{
Andrielly Tássia Oliveira da Silva ${ }^{1}$ (D) orcid.org/0000-0001-6709-7431 \\ Luciana Bazante de Oliveira ${ }^{1}$ (D) orcid.org/0000-0001-9115-896X \\ ${ }^{1}$ Pós-graduação em Gestão da Qualidade e Produtividade, Escola Politécnica de Pernambuco, Pernambuco, Brasil. \\ E-mail do autor principal: Andrielly da Silva andriellytassia@hotmail.com
}

\section{Resumo}

As ferramentas da qualidade são recursos essenciais para a melhoria contínua de processos e produtos, visto que as organizações buscam cada vez mais se manterem competitivas no mercado. Por serem versáteis, as ferramentas podem ser aplicadas em diversas situações, contribuindo para a coleta, análise e tratamento de informações. Este artigo foi elaborado com base em uma intervenção realizada em uma indústria de alumínio, com a aplicação das ferramentas da qualidade na análise de produtos não conformes, com o intuito de reduzir o número de reclamações de clientes por problemas relativos à variações na qualidade. Após a aplicação das ferramentas na análise e tratamento das não conformidades em produtos, verificou-se a redução do número de reclamações de clientes por não conformidades, atestando que a implantação das ferramentas da qualidade contribuiu para uma melhoria significativa nos produtos.

Palavras-Chave: Ferramentas da qualidade; Indústria de alumínio; Não conformidades.

\begin{abstract}
Quality tools are essential resources for continuous improvement of process and products as organizations increasingly seek to remain competitive in the market. Because they are versatile, the tools can be applied in many situations, contributing to the collection, analysis and treatment of informations. This article is based on an intervention in an aluminum industry, applying the quality tools in the analysis of nonconforming products, in order to reduce the number of customer complaints about problems related to quality variations. After the application of the tools in the analysis and treatment of products nonconformities, there was a reduction in the number of customer complaints, attesting that the implementation of quality tools contributed to a significant improvement in the products.
\end{abstract}

Key-words: Quality tools; Aluminum industry; Nonconformities. 


\section{Introdução}

$O$ incessante progresso das transformações econômicas e tecnológicas vem contribuindo para o aumento da necessidade das empresas em aderirem a novos métodos e ferramentas, buscando garantir a qualidade em seus processos e produtos, tornando-as mais competitivas e produtivas. Dessa maneira, com a busca pela melhoria contínua, as ferramentas da qualidade foram desenvolvidas para facilitar a coleta de dados e aplicação de conceitos, contribuindo assim para a melhoria da qualidade de serviços, processos e produtos [1].

As ferramentas são frequentemente utilizadas na indústria porque podem contribuir, por meio de técnicas estruturadas, para facilitar a remoção de causas dos problemas, obtendo assim uma maior produtividade e, consequentemente a redução de perdas. Desse modo, pode-se entender que essas técnicas, deveriam ser ensinadas às organizações e aplicadas em sua rotina, possibilitando na identificação de oportunidades, aperfeiçoamento e eliminação de perdas [2].

Assim, como qualquer outro, o setor da indústria de alumínio necessita de um acompanhamento de seus processos e produtos, porém demanda um alto padrão de qualidade dos seus materiais, devido ao alto valor de mercado [3].

O Brasil é o décimo primeiro produtor de alumínio primário, é o quarto produtor de bauxita, e terceiro produtor de alumina, cenário esse, causado pela perda de competitividade do mercado brasileiro. A principal razão para esse acontecimento é derivada do aumento do custo de energia, da instabilidade da economia, e da falta de uma política de longo prazo para o setor. A indústria do alumínio vem sendo prejudicada desde 2015, por causa da crise política que o país vem enfrentado e que afeta diretamente na redução dos principais indicadores do mercado [4].

Portanto, as ferramentas da qualidade são essenciais para o controle e o gerenciamento da produção também na indústria de alumínio, já que podem contribuir para a incorporação de melhorias e promoção de melhores resultados.

\section{Metodologia}

Uma empresa que fabrica e comercializa alumínio, apresentava problemas efetivos de qualidade, que resultava no crescimento do número de reclamações de clientes. A empresa em questão decidiu realizar uma análise e tratamento da situação de maneira estruturada, dessa maneira, foram aplicadas as ferramentas da qualidade para análise e solução dos problemas encontrados.

Este trabalho trata-se de uma pesquisa-ação aplicada na empresa de alumínio, no qual foi inicializada uma pesquisa exploratório-descritiva, com sua coleta de dados desenvolvida a partir das reclamações e dos registros internos relacionados aos problemas e dados de produção. Em seguida, foi realizada a aplicação prática das ferramentas da qualidade.

\section{Revisão de Literatura}

\subsection{Segmento de Indústrias de alumínio}

O alumínio é uma commodity global, uma mercadoria fabricada em larga escala e comercializada em nível mundial, estando presente em 236 plantas localizadas em 42 países e em 5 continentes. É um metal cuja industrialização começou no fim do século XIX e que vem crescendo ao longo do tempo, apresentando um alto valor de lucratividade para o mercado mundial. Ele pode ser aplicado de muitas formas, por isso é um dos materiais mais utilizados no mundo todo. Já que é caracterizado por ser leve, durável e brilhante, o alumínio tem uma excelente performance e propriedades superiores na maioria das aplicações, encontrando-se em diversos setores industriais, como: bens de consumo, automotivo e transportes, construção civil, embalagens, indústria elétrica, máquinas, etc [5].

Mesmo com os problemas enfrentados pelo setor, a produção do alumínio no Brasil e a demanda interna por produtos transformados de alumínio apresentou uma melhora. Em 2017 o consumo foi de $1.263 \mathrm{mil}$ toneladas contra 1.205 mil toneladas em 2016. Já a exportação e importação apresentaram uma queda de $22,63 \%$ e 0,38 \% respectivamente, em relação a 2016 [4]. 
Considerando as oportunidades de mercado e a perda de competitividade do Brasil no segmento, a preocupação com a qualidade do seu produto não é apenas um diferencial, mas uma necessidade.

\subsection{Gestão da Qualidade}

Com o processo de globalização, a qualidade como fator de melhoria de processos e produtos passou por inúmeras modificações e reestruturações, baseadas principalmente pelas necessidades de renovação das instituições. Dessa maneira, a qualidade passou a ser vista como um todo e não apenas um processo isolado e independente.

O processo de reestruturação da qualidade passou por quatro fases, denominadas eras da qualidade, que apresentaram diferentes abordagens, provocando mudanças nas práticas industriais, tal evolução pode ser visualizada na Figura 1. Em meados dos anos 20, o foco da qualidade era a inspeção, com interesse na verificação dos materiais e produtos, buscando a uniformidade. Entre os anos 30 a 40 o foco passou para o controle da qualidade, com ênfase na uniformidade dos produtos, usando menos inspeção e buscando tal controle por meio de ferramentas e técnicas estatísticas [6].

Por volta dos anos 50 a 60 o foco passou para a garantia da qualidade, sendo o principal interesse a coordenação de fabricação, desde o projeto até o cliente, com a contribuição de todos os grupos funcionais para impedir falhas na qualidade. $\mathrm{Na}$ década de 70 o foco passou para a gestão da qualidade total, com ênfase em atender as necessidades do mercado e dos clientes, bem como na prevenção de não conformidades, através do planejamento estratégico e mobilização da organização, visando associar a qualidade com todas as etapas e processos [6].

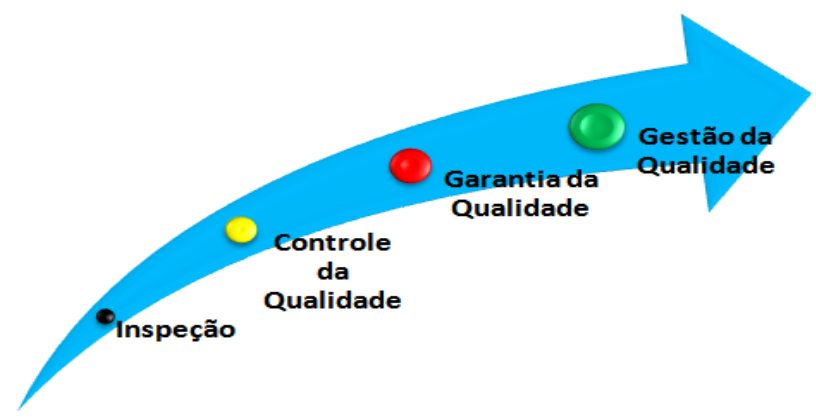

Figura 1: Evolução da qualidade.

Fonte: Adaptado de Paladini (2006)
A gestão da qualidade total é considerada como a última fase da evolução dos conceitos da qualidade. Utiliza como base para melhoria contínua o ciclo PDCA, que pode ser visualizado na Figura 2, cuja finalidade é o gerenciamento de processos e o alcance de metas. O ciclo PDCA preconiza a melhoria contínua dos processos, serviços e produtos por meio de 4 etapas sequenciais: planejar, fazer, checar e agir e passou a ser usado como base para a formação de sistemas de gestão da qualidade [7].

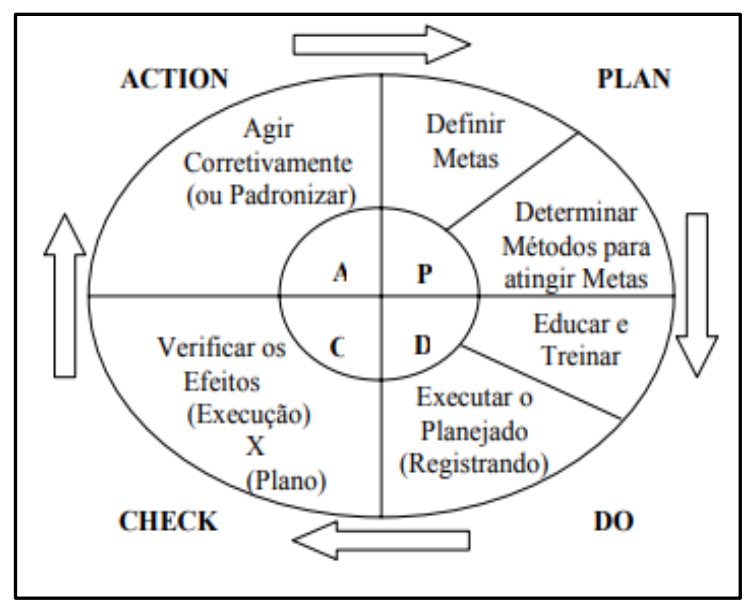

Figura 2: Ciclo PDCA.

Fonte: Adaptado de Mariani (2005)

\subsubsection{Sistema de Gestão de Qualidade}

O sistema de gestão da qualidade (SGQ) pode ser visto como um conjunto de práticas que são aplicadas e desenvolvidas nas empresas para padronização e controle de processos. Essas práticas são definidas conforme as necessidades e expectativas das partes interessadas, buscando a melhoria contínua dos processos, serviços e produtos. Ele muda o foco da qualidade da operação para toda a organização, contribuindo para a redução de custos e perdas, além de favorecer a otimização de processos e serviços [8].

A introdução de um SGQ é uma decisão estratégica para qualquer empresa, pode contribuir para melhorar seu desempenho global e fornecer meios para o desenvolvimento sustentável da organização. Os benefícios para uma empresa que implanta o SGQ podem ser inúmeros, como: padronização dos processos, melhora na comunicação interna, redução de retrabalho e custo, além de aumentar a satisfação 
do cliente e encontrar oportunidades de melhoramento dos serviços e produtos [9].

Existem cinco táticas estratégicas para contribuir na implantação do SGQ [10]:

- Definir qual o escopo do SGQ da empresa assim como os produtos;

- Envolver todas as pessoas no processo de implantação;

- Realizar um diagnóstico da situação atual da empresa, em relação ao modelo que deseja implantar;

- Mapear os processos relevantes da empresa;

- Definir as metas e os indicadores que serão avaliados e acompanhados pelos SGQ;

- Posteriormente utilizar métodos para avaliar a eficiência e a eficácia da gestão da qualidade.

A implantação de um SGQ em uma organização precisa ser estrategicamente planejada, de maneira a garantir a melhoria dos resultados da organização.

\subsection{Ferramentas da qualidade}

Para a aplicação e manutenção de um sistema de gestão da qualidade, é importante a utilização de ferramentas para auxiliar no controle de processos e cumprimento de objetivos. As ferramentas da qualidade são utilizadas na busca pela melhoria de processos e para resolução de problemas relacionados à qualidade. Elas têm como objetivo principal facilitar a melhor compreensão de processos e a tomada de decisão com base em fatos e dados [11].

As ferramentas básicas para a qualidade possuem o propósito de auxiliar e direcionar a resolução de problemas. Algumas das mais conhecidas são: brainstorming, histograma, folha de verificação, 5 Porquês, plano de ação, gráfico de Pareto e diagrama de causa e efeito.

\subsubsection{Brainstorming}

O brainstorming é uma ferramenta conhecida como tempestade de ideias, que pode auxiliar uma equipe na elaboração de ideias em um curto espaço de tempo. O objetivo principal é de incentivar a criatividade de um grupo, no qual consiste em trabalhar com o intuito de averiguar o entendimento de problemas ou as possíveis causas do que precisa ser corrigido [12].

51

\subsubsection{Histograma}

O histograma é um gráfico de barras no qual se pode observar a distribuição de dados por categoria. É uma ferramenta muito utilizada na estatística de processos, pois torna possível verificar a frequência com que variam os fatores, facilitando o estudo de determinadas situações [13].

A estrutura do histograma irá depender de qual processo será analisado e ajudará na delimitação de um indicador de desempenho para servir de parâmetro na análise dos dados. Também é importante determinar o intervalo de tempo e a quantidade de dados que serão utilizados [13].

\subsubsection{Folha de verificação}

A folha de verificação é um formulário utilizado para a coleta de dados, contribuindo para a verificação e distribuição de um item de controle. O principal objetivo dessa ferramenta é facilitar a coleta, registro e padronização dos dados [13].

Para a elaboração de uma folha de verificação, é necessário primeiro definir o objetivo da coleta de dados que estará sendo realizada, para só então coletar dados suficientes, que representem os resultados aguardados e, posteriormente, definir qual o modelo de folha de verificação será mais apropriado para análise.

\subsubsection{Porquês}

A análise dos 5 Porquês é uma técnica simples e efetiva que contribuí para a identificação das causas de problemas, na análise de causa raiz, muito utilizada na área da qualidade, mas podendo ser aplicada em qualquer área [14].

Os 5 porquês é uma ferramenta criada por Taiichi Ono, considerado o pai do Sistema Toyota de produção, que consiste em realizar a pergunta " Por quê" cinco vezes para identificação e compreensão da causa do problema. Não necessariamente é preciso realizar as cinco perguntas, desde que a causa raiz do problema seja encontrado [14]. 


\subsubsection{Gráfico de Pareto}

O gráfico de Pareto é uma das ferramentas mais utilizadas nas organizações. É um gráfico de barras verticais, onde é possível ordenar dados a partir do valor mais alto até o valor mais baixo, traçando uma curva para demonstrativo das porcentagens acumuladas, conforme pode ser visualizado na Figura 3. A utilização do gráfico de Pareto contribui para facilitar a visualização das causas ou dos problemas que precisam ser investigados em determinado processo [15].

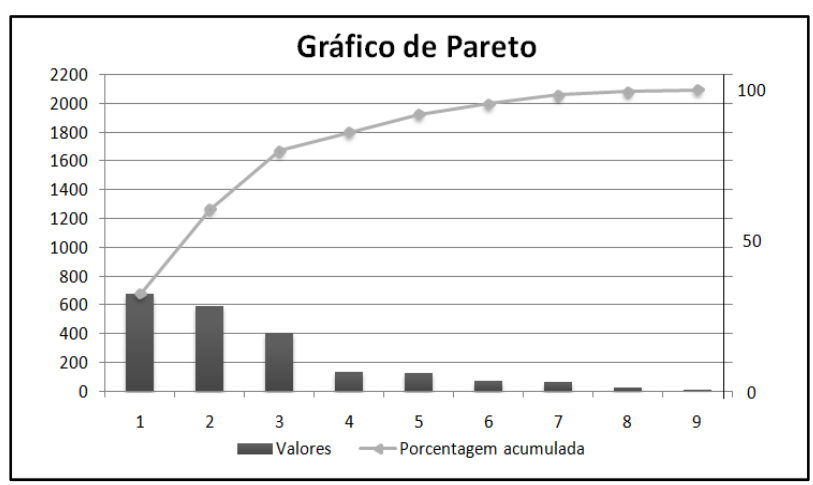

Figura 3: Gráfico de pareto.

Fonte: Adaptado de Corrêa e Corrêa (2012).

É possível visualizar na Figura 3 que as colunas são dispostas da maior para a menor frequência, sendo formada uma linha que apoia no entendimento do princípio 80-20, onde devem ser identificados os poucos itens que muito impactam na situação, em detrimento dos diversos itens que possuem pouco impacto.

\subsubsection{Diagrama de causa e efeito}

O diagrama de causa e efeito, também conhecido como diagrama de Ishikawa ou gráfico de espinha de peixe, foi criado em 1943 pelo engenheiro japonês Kaoru Ishikawa e tem como objetivo principal realizar a análise das operações nos processos produtivos. 0 diagrama de causa e efeito tem uma estrutura parecida com uma espinha de peixe, onde o eixo principal é visto como o fluxo de informações e as espinhas como os aspectos secundários, que contribuem para a análise do problema, como pode ser visualizado na Figura 4 [15].

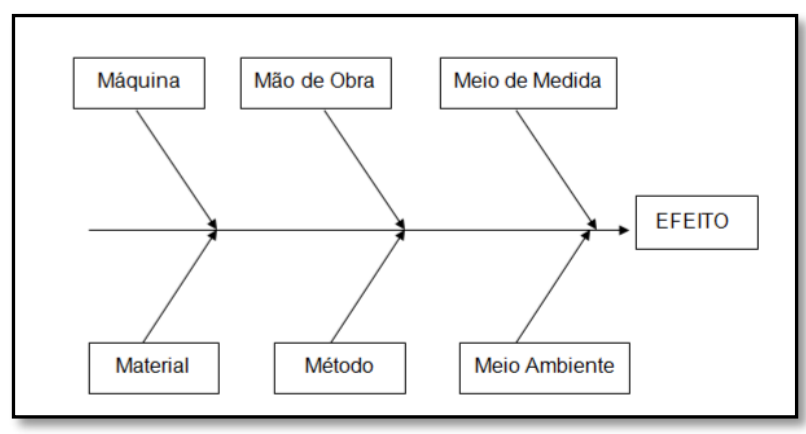

Figura 4: Diagrama de causa e efeito. Fonte: Adaptado de Corrêa e Corrêa (2012).

Para a construção do diagrama, como mostra a Figura 4, é necessário definir o problema central a ser investigado, e depois adicionar nas ramificações os seis $M$ :

- Máquina,

- Material;

- Mão de obra;

- Método;

- Medida e

- Meio ambiente.

Cada uma das ramificações representa um grupo de áreas a serem investigadas para entender as causas de um problema e, dessa maneira, contribuir para a elaboração de ideias para a sua resolução [16].

\subsubsection{Plano de ação}

O plano de ação é uma ferramenta de fácil execução que tem como objetivo principal a elaboração de um plano eficiente e simples, direcionado para a solução dos problemas. Ele pode ser usado para solução de problemas ou melhorias, e consiste em um questionário contendo sete perguntas relacionadas ao processo produtivo, sendo o seu nome oriundo das primeiras de cada uma delas:

- What? (O quê?);

- Who? (Quem?);

- Where? (Onde?);

- When? (Quando?);

- Why? (Por quê?);

- How? (Como?) e

- How much? (Quanto custa?).

É uma ferramenta extremamente útil para as organizações, pois previne falhas por parte das ações 
a serem realizadas e ajuda eliminar dúvidas quanto à execução das atividades [17].

\section{Discussões e Resultados}

A indústria de alumínio em questão apresentava problemas relacionados à qualidade dos seus produtos. Os clientes da empresa detectaram que os produtos apresentavam danos externos e internos, como: quebras, rugas (dobras do alumínio ao longo da folha), machucados, telescopagem (espiras corridas na lateral), furos, aderência, molhabilidade (óleo na bobina de alumínio), rebarbas, variação de espessura, quebras na emenda, entre outros, conforme demonstrado na Figura 5.

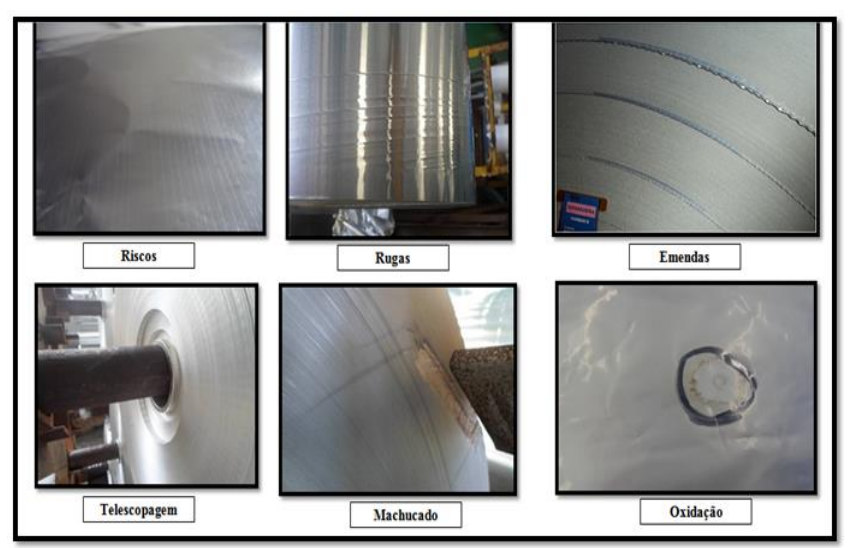

Figura 5: Não conformidades presente nos produtos. Fonte: Autora (2018).

Ao serem recebidos pelos clientes, os produtos são inspecionados tanto superficialmente como internamente. Quando evidenciada alguma não conformidade, é gerado um registro de não conformidade (RNC), que é um documento virtual fornecido pela empresa de alumínio no qual o cliente pode descrever o problema encontrado, informar a quantidade de material que pode vir a ser devolvida, a numeração do material e fotos para constatação e avaliação da não conformidade pela equipe de qualidade.

Esses RNC's são monitorados todos os dias por meio de um portal online chamado share point, pelo qual são gerados relatórios com os dados das reclamações. Todas as reclamações e devoluções de produtos defeituosos são registradas nesse portal, sendo o setor de qualidade responsável por realizar a análise e tratamento dos problemas, preenchendo formulários que são encaminhados para os clientes com as ações adotadas e o esclarecimento das causas da não conformidade, em um prazo de até 10 dias úteis.

Após perceber um aumento significativo do número de reclamações por partes dos clientes, o setor de qualidade de clientes da empresa realizou um levantamento dos formulários de RNCs que foram recebidos no ano de 2017 na linha de folhas, e através da utilização de um gráfico foi possível observar o aumento no quantitativo de RNCs recebidos por problemas efetivos de qualidade, principalmente por rugas no alumínio, como pode ser visualizado na Figura 6.

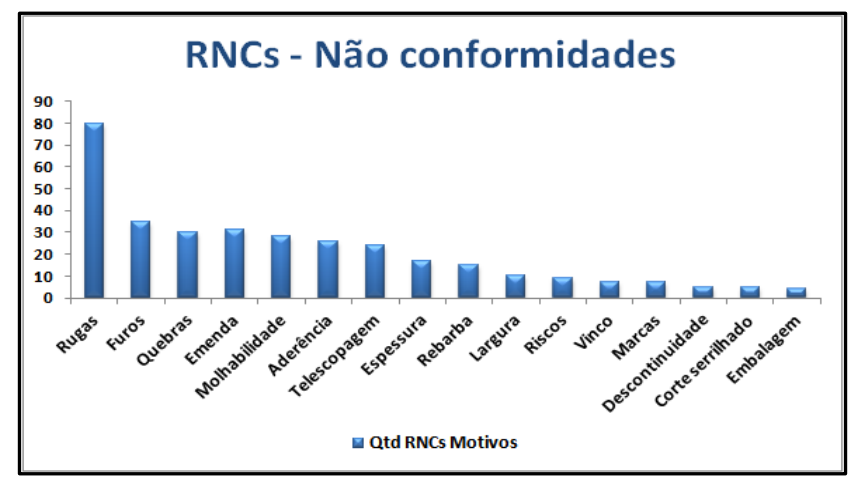

Figura 6: RNCs por não conformidade em 2017. Fonte: Autora (2018).

Dessa maneira, após constatar que rugas era um dos principais causadores de reclamações, o setor de qualidade decidiu restringir a análise apenas no problema de rugas, com a aplicação de ferramentas da qualidade para estudar e tratar o problema. Foram aplicadas as seguintes ferramentas: brainstorming, lista de verificação, gráfico de pareto, 5 porquês, diagrama de causa e efeito e plano de ação.

\subsection{Aplicação das ferramentas}

\subsubsection{Brainstorming}

O brainstorming foi realizado com representantes das áreas da qualidade, produção e processos. Essas pessoas foram identificadas como relevantes para participar da análise porque poderiam contribuir para o entendimento do problema, uma vez que estavam envolvidas com o processo de alguma forma.

A partir do brainstorming foram identificadas algumas causas prováveis para o surgimento das rugas no produto, tais como: vibração nos cilindros das máquinas que separam o alumínio, alta aderência, 
cilindros desnivelados, as facas de corte cegas, alto teor de álcool, ovalização das bobinas e rasgos contínuos no alumínio.

Após o levantamento de dados e discussões das reclamações no brainstorming foi iniciada a análise da não conformidade, com 0 intuito de investigar problemas recorrentes nas máquinas e no material que poderiam estar causando as rugas.

\subsubsection{Coleta de dados}

O processo de coleta de dados para análise se iniciou na verificação de livros de máquinas para saber se no dia e horário algum produto ou a própria máquina havia apresentado problema, se algum inspetor de qualidade foi acionado, se foi necessária análise de laboratório, entre outras informações que são de grande importância para o gerenciamento das não conformidades.

Após a coleta de dados, deu-se início à verificação das informações, sendo a ferramenta adotada a lista de verificação, exibida na Figura 7. Utilizada com o intuito de auxiliar no levantamento e registro de dados referentes às reclamações, além de contribuir para a padronização e organização das informações.

\begin{tabular}{|c|c|c|c|}
\hline \multicolumn{4}{|c|}{ LISTA DE VERIFICAÇĀO - FOLHAS } \\
\hline \multicolumn{4}{|l|}{ Data } \\
\hline \multicolumn{4}{|l|}{ № de RNC } \\
\hline \multicolumn{4}{|l|}{ Não conformidade } \\
\hline \multicolumn{4}{|l|}{ Típo de material } \\
\hline \multicolumn{4}{|l|}{ Periodo de produção } \\
\hline Verificador & & Status & \\
\hline Livro de registro & Defeito & Data de Ocorrência & Comentário do livro de registro \\
\hline \multicolumn{4}{|l|}{ LIVRO DO COSIM } \\
\hline \multicolumn{4}{|l|}{ LIVRO DO LAMINADOR } \\
\hline \multicolumn{4}{|l|}{ IIVRO DA SEPARADEIRA } \\
\hline \multicolumn{4}{|l|}{ LIVRO DO LABORATÓRIO } \\
\hline \multicolumn{4}{|l|}{ LIVRO DA INSPEÇ̃̃o } \\
\hline LIVRO DA MANUTENÇĀ̃O & & & \\
\hline
\end{tabular}

Figura 7: Lista de verificação de Folhas. Fonte: Autora (2018)

Os livros de registros de máquinas, laboratório, inspeção e manutenção foram listados em itens para serem verificados na busca por constatação de alguma ocorrência no determinado período estudado da reclamação de não conformidade, com a finalidade de ter um acompanhamento dos dados que posteriormente serão analisados.

Com a utilização da lista de verificação foram levantados alguns pontos referentes às reclamações por rugas, como período de produção, máquinas e tipo de material. Foi possível constatar, como mostra a Figura 8, que o defeito foi identificado em folhas de 54 alumínio de 9 micras e 6,3 micras. Esse tipo de material é utilizado na produção de embalagens para o ramo alimentício, e são chamadas de folhas finas. Assim como foi identificado o tipo de material que apresentava o defeito, foi possível identificar a máquina geradora do problema, sendo possível comprovar que eram as máquinas que separam e cortam as folhas de alumínio, chamadas de separadeiras.

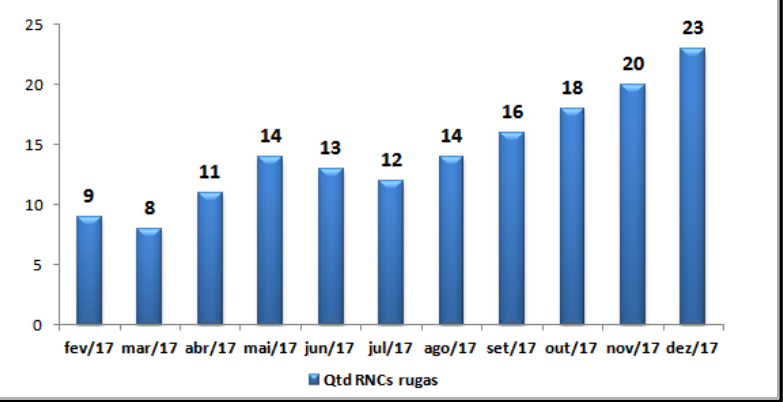

Figura 8: Histograma de rugas em folha 9 micras e 6,3 micras no ano de 2017.

Fonte: Autora (2018).

\subsubsection{Gráfico de Pareto}

Após os dados das listas de verificações serem ordenados e estratificados, foi aplicado o gráfico de pareto, onde esses dados foram utilizados para a identificação dos principais motivos das rugas no alumínio. Dessa maneira, como observado na Figura 9, foi possível ordenar as frequências das ocorrências em ordem decrescente e dessa maneira priorizar a análise das causas.

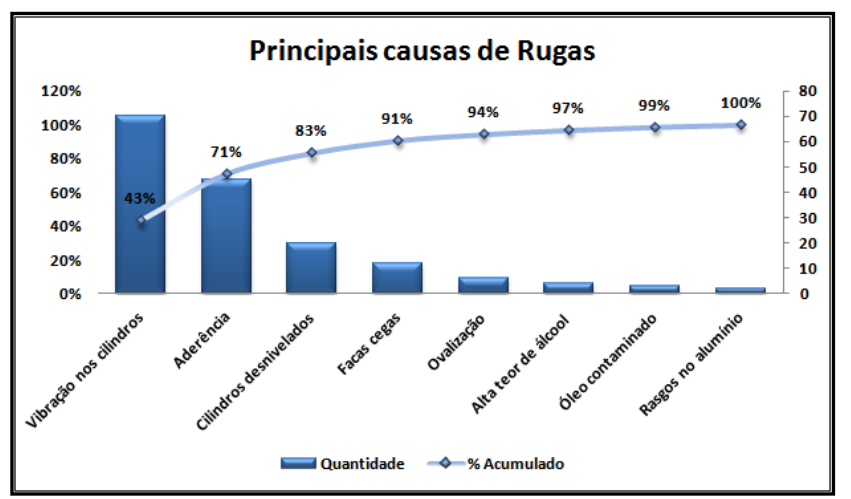

Figura 9: Gráfico de principais motivos de rugas. Fonte: Autora (2018)

Após a construção do gráfico de Pareto, foi possível constatar que a vibração nos cilindros das máquinas de separação do alumínio em conjunto com a alta DOI: $10.25286 /$ repa.v5i4.1310 
aderência resultava no surgimento de rugas no material.

Após a aplicação do gráfico de pareto, foram criadas outras planilhas de coleta de dados, onde os dados foram estratificados por máquina e por turno, o que pode ser visualizado na Figura 10, para entender se 0 surgimento das rugas estava concentrado em algum dos turnos ou alguma máquina separadeira, já que a empresa de alumínio possui cinco separadeiras contribuindo para o controle sobre o quantitativo de ocorrências durante o ano e para a análise da não conformidade.

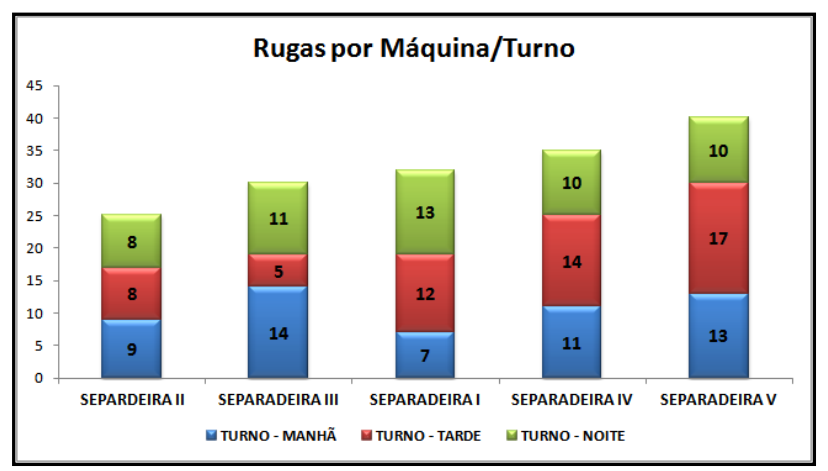

Figura 10: Estratificação de rugas por Máquina /Turno. Fonte: Autora (2018)

Posteriormente a estratificação das ocorrências de rugas por máquina e turno foi possível constatar uma frequência maior de incidentes nas máquinas separadeira V e na separadeira IV, respectivamente, nos turno da tarde. Com a utilização dessa ferramenta, tornou-se mais fácil subdividir os dados e dessa maneira ter um maior controle sobre a variação das ocorrências, além de facilitar a identificação da localização dos problemas e na criação de padrões a serem estudados.

\subsubsection{Análise de causas}

Após o entendimento do problema, o diagrama de causa e efeito e análise dos 5 Porquês, foram incorporados a um formulário de Análise de causa raiz (ACR), que é utilizado pela empresa para análise de rejeições e gatilhos internos decorrentes de material não conforme, que contribui para a eliminação de reincidência de não conformidades e para facilitar a investigação das causas.

Dessa maneira, para cada RNCs foi atribuído um formulário de ACR contendo o diagrama de causa e efeito e análise dos 5 Porquês, que será preenchido com base nos dados coletados e utilizado para avaliar a relação da não conformidade detectada e os fatores ou causas do processo que podem ser responsáveis pelo evento, sendo possível visualizar na Figura 11.

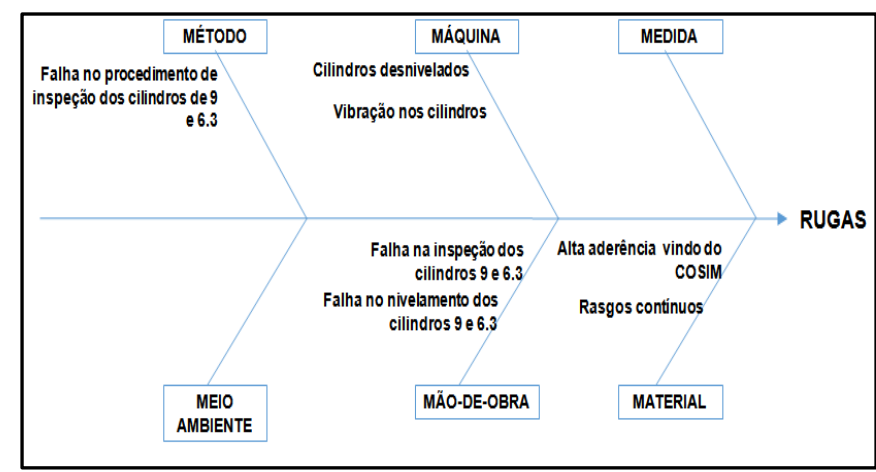

Figura 11: Diagrama de causa e efeito- Rugas Fonte: Autora (2018)

Através da utilização do diagrama de causa e efeito em conjunto com os 5 Porquês, as equipes de qualidade, produção e processos constataram que a causa raiz dos problemas da vibração nos cilindros era o seu desnivelamento, além do baixo teor de óleo presente nas folhas de alumínio que resultava em uma maior aderência das folhas e consequentemente uma maior dificuldade na separação. Dessa maneira o conjunto desses dois fatores resultava no surgimento de rugas no material.

\subsubsection{Ações corretivas}

Após a análise do diagrama de causa e efeito com a descoberta da causa raiz foi então aplicada à ferramenta, plano de ação.

As principais ações que foram elaboradas para a correção e a prevenção dos problemas com a vibração dos cilindros e a alta aderências nas folhas de alumínio foram:

- Revisar procedimento do nivelador de perfil de cilindros de folhas 9 micras e 6,3 micras;

- Comprar novo nivelador de perfil de cilindros de folhas 9 micras e 6,3 micras;

- Revisão do procedimento de teor de óleo do COSIM;

- Criação de um procedimento de teste de aderência para as separadeiras;

- Criar um novo procedimento de inspeção dos cilindros de 9 micras e 6,3 micras;

- Manutenção preventiva no controlador de destilação de óleo das separadeiras; 
- Procedimento de inspeção de rugas nas separadeiras e laminadores.

As ações que foram geradas após a análise do diagrama, foram arquivadas em uma planilha de monitoramento chamada ações de qualidade. Após o arquivamento das ações, é realizado um follow up semanal com os responsáveis até a conclusão da ação. Após ela ser concluída, o responsável deve encaminhar para a equipe qualidade de clientes a evidência da ação realizada, para ser arquivada tanto fisicamente como eletronicamente.

Em virtude dos fatos estudados com a utilização das ferramentas da qualidade, foi possível identificar, como pode ser visualizada na Figura 12, uma redução de $56 \%$ no número de RNCs das rugas nos produtos, recebidas pelo setor de qualidade no ano de $2018 \mathrm{em}$ comparação com o ano de 2017.

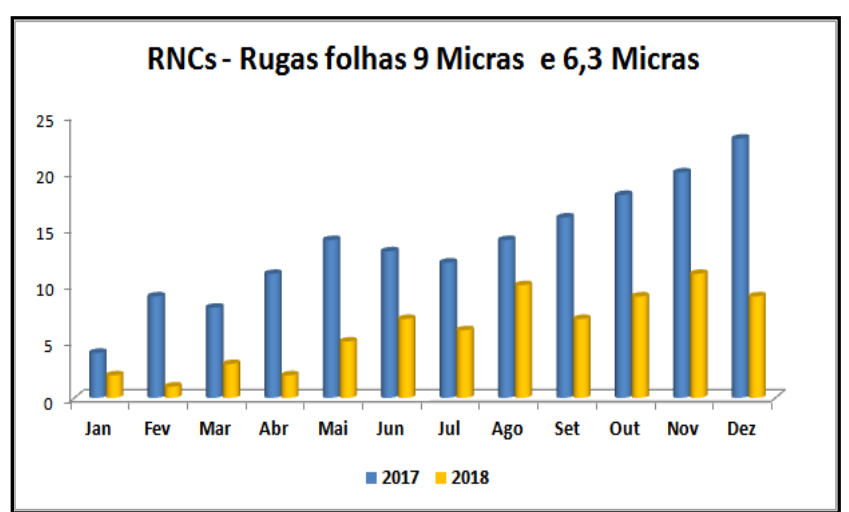

Figura 12: Comparação da Qtd de RNCs de rugas de 2017 e 2018.

Fonte: Autora (2018)

\section{Conclusão}

Posteriormente à aplicação das ferramentas da qualidade na análise das reclamações de não conformidade da linha de folhas, foi possível constatar através dos dados apresentados que a aplicação da metodologia adotada foi bem sucedida, visto que 0 resultado final foi satisfatório e relevante. Dessa maneira, a metodologia apresentada será aplicada nas análises das RNCs para correção de problemas efetivos de qualidade da linha de chapas da empresa. Esse resultado ocorreu porque as causas principais do surgimento das rugas foram identificadas e corrigidas, como também foram implantadas ações com o intuito de evitar a reincidências dos defeitos.
As ferramentas utilizadas nesse trabalho foram de grande utilidade para 0 aperfeiçoamento dos processos e produtos da empresa. São técnicas eficientes, que possibilitaram bons resultados, permitindo a visualização, de forma clara, que a gestão da qualidade em conjunto com a aplicação de ferramentas da qualidade, pode contribuir de forma efetiva para a melhoria contínua de produtos e processos.

\section{Referências}

[1] SANTOS, Patrícia Fonseca. Estudo da Gestão da Qualidade total e sua influência na produtividade industrial. 2017. 44 páginas. Trabalho de Conclusão de Curso (Especialização em Engenharia de Produção) Universidade Tecnológica Federal do Paraná. Ponta Grossa, 2017.

[2] MAICZUK, J.; JÚNIOR, P. P. A. Aplicação de Ferramentas de Melhoria de Qualidade e Produtividade nos Processos Produtivos: Um Estudo de Caso. Qualit@s Revista Eletrônica. Paraíba, v. 14, 2013.

[3] MONTGOMERY, Douglas C. Introdução ao controle estatístico da qualidade. 4. ed. Rio de Janeiro: LTC, 2009.

[4] ABAL, Associação Brasileira do Alumínio. Disponível em: <http://abal.org.br/estatisticas/nacionais/perfilda-industria/> . Acesso em: 28 de janeiro de 2019.

[5] ABAL, Associação Brasileira do alumínio. Alumínio Brasileiro: Soluções para uma vida sustentavel. São Paulo, 2017. p. 12.

[6] PALADINI, E. P. Gestão da qualidade: teoria e casos. Rio de Janeiro: Elsevier, 2006. p. 7.

[7] MARIANI, Celso Antonio. Método PDCA e Ferramentas da qualidade no gerenciamento de processos industriais: Um estudo de Caso. RAI - Revista de Administração e Inovação, São Paulo, v. 2, n. 2, 2005.

[8] VIEIRA, Ariana Martins et al. Diretrizes para desenvolvimento coletivo de melhoria contínua em arranjos produtivos locais. Gestão \& Produção, v. 20, n. 2, 2013. p. 469-480.

[9]SGQ- Sistema de gestão da qualidade. Biologística. Disponivel em: <https://blog.biologistica.com.br/sgq- 
sistema-da-gest\%C3\%A3o-da-qualidade-

d0a0817f1ff5>. Acesso em: 02 de julho de 2019

[10] 5 Técnicas para implantar um sistema de gestão da qualdiade. Pollon Consultoria. Disponível em: < http://blog.pollonconsultoria.com.br/5-tecnicas-paraimplantar-um-sistema-de-gestao-da-qualidade//>. Acesso em: 09 de abril de 2019.

[11] MAICZUK, Jonas; JÚNIOR, Pedro Paulo Andrade. Aplicação de ferramentas de melhoria de qualidade e produtividade nos processos produtivos: um estudo de caso. Qualitas Revista Eletrônica, v. 14, n. 1, 2013.

[12] CUSTODIO, Marcos Franqui, Gestão da qualidade e produtividade. 1. ed. São Paulo: Editora: Pearson Education do Brasil, 2015

[13] CARPINETTI, L. C. R. Gestão da qualidade: Conceitos e Técnicas. 2 ed. São Paulo: Atlas, 2012.

[14] CAMPOS, Amanda Layla Pinheiro. Utilização de ferramentas da qualidade para proposição de melhorias no processo de uma aciaria de grande porte com vistas à redução de ocorrências de clogging. 2016. 57 f. Monografia (Graduação em Engenharia de Produção) Instituto de Ciências Exatas e Aplicadas, Universidade Federal de Ouro Preto, João Monlevade, 2016.

[15] CARVALHO, M. M. et al. Gestão da qualidade: teoria e casos. 2 ed. Elsevier: ABEPRO, 2012.

[16] CORRÊA, H. L.; CORRÊA, C. A. Administração de produção e operações: Manufatura e serviços, uma abordagem estratégica. 3 ed. São Paula: Atlas, 2012.

[17] STRUETT, M. A. M. Gestão da qualidade.

Maringá: Cesumar, 2011. 


\section{PLANO DE AÇÕES DE QUALIDADE}

\begin{tabular}{|c|c|c|c|c|c|c|c|}
\hline \multicolumn{4}{|c|}{ 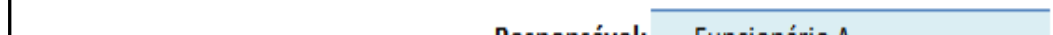 } & \multirow{3}{*}{$\begin{array}{l}\text { Objetivo: } \\
\text { Indicador: }\end{array}$} & \multirow{2}{*}{ Redução do № de RUGAS } & & \\
\hline & Responsável: & \multicolumn{2}{|l|}{ Funcionário $\mathrm{A}$} & & & & \\
\hline & Responsável: & \multicolumn{2}{|l|}{ Funcionário B } & & & & \\
\hline \multirow{2}{*}{0 que } & \multirow{2}{*}{ Quem } & \multicolumn{2}{|c|}{ Quando } & \multirow{2}{*}{ Onde } & \multirow{2}{*}{ Por que } & \multirow{2}{*}{ Hoje } & \multirow{2}{*}{$\begin{array}{l}\text { Situação } \\
\text { Atual }\end{array}$} \\
\hline & & Início & Fim & & & & \\
\hline $\begin{array}{l}\text { Criar procedimento de } \\
\text { inspeção dos cilindros de } 9 \\
\text { micras e } 6,3 \text { micras }\end{array}$ & Funcionário 1 & $16 / 02 / 2018$ & $20 / 02 / 2018$ & Manutenção & $\begin{array}{c}\text { Para eliminar a falha na } \\
\text { inspeção visual dos } \\
\text { cilindros que acabam } \\
\text { causando rugas na folha de } \\
\text { alumínio. }\end{array}$ & $100 \%$ & Concluída \\
\hline $\begin{array}{l}\text { Criar procedimento de teor } \\
\text { de óleo do COSIM }\end{array}$ & Funcionário 2 & $14 / 02 / 2018$ & $16 / 02 / 2018$ & COSIM & $\begin{array}{c}\text { Revisar o procedimento } \\
\text { por conta da alta aderencia } \\
\text { vindo do COSIM }\end{array}$ & $100 \%$ & Concluída \\
\hline $\begin{array}{l}\text { Revisar procedimento do } \\
\text { nivelador de perfil de } \\
\text { cilindros de folhas } 9 \text { micras } \\
\text { e } 6,3 \text { micras }\end{array}$ & Funcionário 3 & $13 / 02 / 2018$ & $19 / 02 / 2018$ & REFIM & $\begin{array}{c}\text { Os cilindros da refim estão } \\
\text { chegando nas separadeiras } \\
\text { desnivelados. }\end{array}$ & $100 \%$ & Concluída \\
\hline $\begin{array}{l}\text { Comprar novo nivelador de } \\
\text { perfil de cilindros de folhas } \\
9 \text { micras e } 6,3 \text { micras }\end{array}$ & Funcionário 3 & $13 / 02 / 2018$ & $02 / 03 / 2018$ & REFIM & $\begin{array}{c}\text { Os cilindros da refim estão } \\
\text { chegando nas separadeiras } \\
\text { desnivelados. }\end{array}$ & $100 \%$ & Concluída \\
\hline $\begin{array}{l}\text { Manutenção preventiva do } \\
\text { controlador de } \\
\text { destiladação de óleo das } \\
\text { separadeiras }\end{array}$ & Funcionário 4 & $14 / 02 / 2018$ & $15 / 02 / 2018$ & SEPS & $\begin{array}{l}\text { Baixa quantidade de óleo } \\
\text { sendo destilada e } \\
\text { consequentemente } 0 \\
\text { aumento da aderência. }\end{array}$ & $100 \%$ & Concluída \\
\hline $\begin{array}{l}\text { Criar procedimento de } \\
\text { teste de aderência das } \\
\text { separadeiras }\end{array}$ & Funcionário 5 & $12 / 02 / 2018$ & $14 / 02 / 2018$ & SEPS & $\begin{array}{c}\text { Folhas } 9 \text { micras e 6,3 } \\
\text { micras apresentando alta } \\
\text { aderência e causando } \\
\text { rugas. }\end{array}$ & $100 \%$ & Concluída \\
\hline $\begin{array}{c}\text { Criar procedimento de } \\
\text { inspeção de rugas nas } \\
\text { separadeiras e laminadores }\end{array}$ & Funcionário 5 & $12 / 02 / 2018$ & $15 / 02 / 2018$ & SEPS E LAMS & $\begin{array}{c}\text { Folhas } 9 \text { micras e 6,3 } \\
\text { micras apresentando rugas. }\end{array}$ & $100 \%$ & Concluída \\
\hline
\end{tabular}

